University of Nebraska - Lincoln

DigitalCommons@University of Nebraska - Lincoln

$11-1-2003$

\title{
Effects of environmental measures on intelligence in young children: Growth curve modeling of longitudinal data
}

\author{
K. A. Espy \\ University of Nebraska-Lincoln, kespy2@unl.edu \\ Victoria J. Molfese \\ University of Nebraska-Lincoln, vmolfese2@unl.edu \\ L. DiLalla
}

Follow this and additional works at: https://digitalcommons.unl.edu/dcnlfacpub

Part of the Neurosciences Commons

Espy, K. A.; Molfese, Victoria J.; and DiLalla, L., "Effects of environmental measures on intelligence in young children: Growth curve modeling of longitudinal data" (2003). Developmental Cognitive Neuroscience Laboratory - Faculty and Staff Publications. 13.

https://digitalcommons.unl.edu/dcnlfacpub/13

This Article is brought to you for free and open access by the Developmental Cognitive Neuroscience Laboratory at DigitalCommons@University of Nebraska - Lincoln. It has been accepted for inclusion in Developmental Cognitive Neuroscience Laboratory - Faculty and Staff Publications by an authorized administrator of DigitalCommons@University of Nebraska - Lincoln. 


\title{
Effects of Environmental Measures on Intelligence in Young Children: Growth Curve Modeling of Longitudinal Data
}

\author{
Kimberly Andrews Espy \\ Southern Illinois University \\ Victoria J. Molfese \\ University of Louisville \\ Lisabeth F. DiLalla \\ Southern Illinois University
}

Effects of different environmental measures on individual intellectual growth patterns were examined in 105 young children participating in a longitudinal study. Intelligence (Stanford-Binet, $4^{\text {th }}$ edition) was measured at ages 3 through 6 years, and child's environment (HOME and SES) was assessed at age 3 years. Growth curve analyses revealed that HOME scores exerted a constant influence on the expected composite, verbal, and nonverbal intellectual skills at each age. Only SES influenced the rate of growth, specifically nonverbal intellectual skills. The magnitudes of these effects were moderate, but consistent, regardless of whether age-standardized or subscale raw scores were analyzed. These findings confirm that HOME and SES scores are more than just different types of measures of the child's environment.

Performance on cognitive tests in childhood typically is better predicted by measures of the home environment and by variables that influ-

Kimberly Andrews Espy, Department of Psychiatry; Victoria J. Molfese, Center for Research in Early Childhood; and Lisabeth F. DiLalla, Department of Psychiatry.

This research is supported by grant R01 HD17860 from the National Institute of Child Health and Human Development.

We thank the participating children and their parents in the southern Illinois area. We also thank Tina Carpenter, Melissa Taylor, Theresa Senn, and Arlene Modglin for their help in test administration, data reduction, figure preparation, and project management. The helpful comments of three anonymous reviewers also are acknowledged.

Correspondence concerning this article should be addressed to: Dr. Victoria J. Molfese, Nystrand/Ashland Chair, School of Education, Room 236, University of Louisville, Louisville, KY 40208 or Dr. Kimberly Andrews Espy, Department of Psychiatry, Mailcode 6503, Southern Illinois University School of Medicine, Carbondale, IL 62901-6503. Email: tori@louisville.edu.

Merrill-Palmer Quarterly, January 2001, Vol. 47, No. 1, pp. 42-73.

Copyright @ 2001 by Wayne State University Press, Detroit, MI 48201 
ence the intellectual level of the home environment than by biomedical risk factors or infant developmental indices. In studies of normal and "atrisk" children (including preterm, low birthweight, and low socioeconomic status $[S E S]$ ), strong correlations between markers for home environment quality (SES, maternal intelligence, characteristics of the home, and parenting practices) and performance on intelligence tests in infancy and early childhood are reported (e.g., Bradley, 1993; Bradley et al., 1993; Gottfried, 1984; Molfese, DiLalla, \& Bunce, 1997; Molfese, DiLalla, \& Lovelace, 1995; Schiamberg \& Lee, 1991). The consistency in findings is remarkable in part because of the variety of measures used across studies to index home environment, including both molecular and molar measures (Bronfenbrenner, 1986). Results from these studies make a strong case for the influence of home environment on development, thereby suggesting that the child's environment, even when considered in the larger context, influences the development of intelligence.

Although the value of home environment in predictive models has been demonstrated with preschool and school-aged children, several issues have not been addressed. First, most studies of the effects of home environment on intellectual development have focused on group performance more than on the performance of individuals. Indeed, data primarily from groups of children have been used to describe the differential effects of environmental variables according to how directly they influence the child (Bradley, 1993; Gottfried \& Gottfried, 1984; Scarr, 1985). Scores on the Home Observation for Measurement of the Environment (HOME) Inventory (Caldwell \& Bradley, 1978) have been classified as proximal indices of the child's environment because they reflect conditions directly experienced by the child. Measures of SES, maternal IQ, and various demographic characteristics have been classified as distal environmental variables because their effects on the child's intellectual development are indirect. Evidence from these studies also indicates that proximal and distal variables play different roles in influencing intellectual development from infancy to childhood. Whether HOME scores or SES better predict intelligence at a given age depends on participant characteristics (Gottfried \& Gottfried, 1984). In a recent report using data from our longitudinal study, proximal measures of home environment remained the most important predictor of intelligence scores of children ages 3 through 8 years, with the influence of home environment lessening after age 4 years. From age 5 years onward, the influence of SES increased (Molfese et al., 1997). However, in this and other studies, the differential role of HOME and SES variables on growth or change in intelligence scores in individual children has not been addressed. How proximal and 
distal measures of home environment influence individual children's growth is investigated here.

The second issue addressed in the present study is what the effects of young children's environments are on intelligence test performance across age. Bradley et al. (1989) showed that extreme scores on HOME and SES had differential effects on children's intelligence test performance. In these comparisons, 3-year-old children whose 12-month SES and HOME scores fell one standard deviation or more below the mean had lower 3-year intelligence scores than children whose scores were one standard deviation or more above the mean. Using longitudinal data and separating the children into three groups based on deviations of HOME and SES scores from the mean, Molfese et al. (1997) reported that children in the lowest group had intelligence scores that decreased over age and that differed significantly from the other two groups after age 3 years. These differences were apparent through 8 years of age. Although the effects of environmental variables on groups or clusters of children have been examined (e.g., McCall, Appelbaum \& Hogarty, 1973), the effects of these variables on the rates of change for individual children of varying initial intellectual skill have not been investigated. Such a study could test whether the child's environment affects intellectual development such that children with enhanced environments show increases in intelligence scores progressively with age whereas children with impoverished environments show progressive declines in intelligence scores. The availability of longitudinal data spanning the preschool and early elementary school period offers an opportunity to examine how environmental variables influence intelligence test performance of individual children, thus allowing for an investigation into sources of continuity and change in intelligence development (Elder, 1998).

Growth curve analysis can be used with longitudinal data to study change in individuals. In these analyses, growth curve trajectories are used that are calculated for the intellectual performances of individual children across age and then related to participant characteristics (Bryk \& Raudenbush, 1987; Francis, Fletcher, Steubing, Davidson, \& Thompson, 1991). At any particular age, a child's IQ score is assumed to be composed of the "true" intelligence score and error that causes the observed IQ score to deviate from the true score. Intelligence tests are normed on crosssectional samples; therefore, the manner by which age-standardized performance changes longitudinally with age in the same children is not known. One reasonable, conservative expectation, based on the psychometric foundations of intelligence testing, is that intelligence is fixed (Sternberg \& Kaufman, 1998) with the growth trajectory of the population across age of "true" IQ scores more or less flat, with any deviation from a 
flat growth profile representing measurement error. This view has been questioned by findings showing changes in intelligence test scores over generations, with each successive generation obtaining higher scores (the "Flynn effect"; Flynn, 1987). These changes are thought to be related to environmental factors and have been cited as the rationale for revisions of standard intelligence tests (e.g., Wechsler, 1991). However, these findings pertain to changes across populations at different times rather than changes within individuals across age. Direct investigations of changes in intelligence test scores in individual children across age are rare, as are investigations of the sources of individual change.

Under study here is the applicability of findings from our research and from other laboratories that the environment is an important influence on the development of intelligence across age. If environmental variables, in fact, affect intellectual development in individual children, then at least part of the change with age in intellectual performance will be related systematically to these environmental variables and will not be due to measurement error alone. The study of the growth trajectories of individuals is expected to yield additional insight into the relation among different environmental variables and the growth of intelligence beyond what is known based on group and cross-sectional data. The present study examined the extent to which individual patterns of intellectual growth were influenced differentially by the participant characteristics commonly found to affect intellectual performance in children, namely, HOME scores and SES. It was anticipated that the child's environment would systematically influence developmental change in intellectual performance.

\section{METHOD}

\section{Participants}

The children participating in this study were part of a longitudinal study of cognitive development conducted in a stable, rural, midwestern community. For this study, scores of children tested longitudinally from ages 3 through 6 years were used. The children in the longitudinal study were recruited at birth during a 5-year period (1984-1988) from families willing to participate and who expected to be available for yearly followup testing sessions. The children were selected at birth because they were either normal, healthy, full-term infants or because they had complications resulting in hospitalization in the Level II Neonatal Intensive Care nursery but that, in themselves, were not likely to result in permanent cognitive impairments. Children with significant neonatal complications 
Table 1. Sample Characteristics

\begin{tabular}{lrc}
\hline Predictor & $M$ & $S D$ \\
\hline HOME total score & 45.60 & 4.36 \\
Learning materials & 8.78 & 1.70 \\
Communication competence & 6.26 & 0.83 \\
Academic stimulation & 6.65 & 0.84 \\
Physical environment & 5.89 & 0.87 \\
Warmth and affection & 4.11 & 0.87 \\
Modeling & 3.35 & 1.12 \\
Variety in experience & 7.03 & 0.99 \\
Acceptance of child & 3.63 & 0.76 \\
Socioeconomic status & 3.58 & 1.18 \\
Maternal education & 3.69 & 1.41 \\
Paternal education & 3.43 & 1.61 \\
Family income & 4.62 & 1.56 \\
Evaluation ages (months) & & \\
3 years & 36.06 & 0.52 \\
4 years & 48.11 & 0.51 \\
5 years & 60.03 & 0.27 \\
6 years & 72.17 & 0.65 \\
\hline
\end{tabular}

Note: $N=105$.

(e.g., intraventricular hemorrhage, severe and persisting respiratory distress, CNS or metabolic complications likely to be chronic, or genetic abnormalities) were excluded. The majority of the children were from intact or reconstituted families who had Hollingshead two factor (Education and Occupation) scores distributed across Categories II through IV. All children were Caucasian. Table 1 contains the characteristics of the children included in the study. The sample mean age was 3.01 years (SD $=0.04$ ) at study entry.

The 122 children in the ongoing longitudinal sample who had complete SES and HOME data at the ages under study were considered for inclusion in the present report. Although most of the children participated in testing at each age, some children had missing scores due to unavailability for a testing session or lack of cooperation during testing. Children with fewer than three of the four intelligence scores $(n=1$ with one IQ score, $n=16$ with two IQ scores) were excluded from the sample reported here. This criterion was used for sample exclusion because a minimum of three data points is necessary to effectively model quadratic growth (Willett, 1988). Therefore, a total of 105 children (46 males, 59 females) were included in this sample. Comparisons between the 105 children who had three or more intelligence scores and the 17 children 
who were excluded from participation in this report revealed no differences in sex, maternal and paternal education, family income, overall SES, HOME total score, or overall intelligence at each age.

\section{Measures}

Environment measures. Two measures of the child's environment were used. Socioeconomic (SES) measures were calculated for each participant using parental education, parental occupation (using the Hollingshead scheme of occupational categories; Bonjean, Hill, \& McLemore, 1967), and family income. Education was scored on a 6 -point scale $(0=$ some high school through $6=$ education beyond college). Occupation was scored on a 6 -point scale $(0=$ unskilled through $6=$ higher executives of large concerns, proprietors, and major professionals). Income was scored on a 6 -point scale $(0=$ less than $\$ 5,000$ through $6=$ over $\$ 35,000)$. Although the top income level may seem low compared with urban samples, $14 \%$ of participant families were in the highest group, with the remainder distributed among the other lower income levels. These variables were averaged to provide a single SES score. If one of the five measures was missing, the others were averaged to form the overall SES score. Information on SES provided by the parents at the time of the child's third birthday was used. If SES information was not available at 3 years, the next closest, younger age on which SES information was available was used. Several researchers (Aylward, 1988; Matheny, 1989; Molfese, Holcomb, \& Helwig, 1994) have found that SES measures strongly predict preschool intelligence scores, whether used as a summary score (e.g., a Hollingshead score or a summing of individual index measures) or when individual index measures are used (e.g., parental education, parental occupations, family income).

The second measure was the Home Observation for Measurement of the Environment (HOME) Inventory, Preschool Version (Caldwell \& Bradley, 1978). The HOME was administered when children were 3 years of age. The HOME consists of 55 items that are either interview questions that are answered by a parent, usually the mother, or observational items. The inventory is administered in the home because of the items pertaining to observations made of the home. The scale is composed of eight subscales: Learning Materials, Stimulation of Communicative Competence, Physical Environment, Warmth and Acceptance, Academic Stimulation, Modeling, Variety in Experience, and Acceptance of Child. The HOME total score was used in this study.

Test of intellectual abilities. The Stanford-Binet Intelligence Scale, $4^{\text {th }}$ Edition (Thorndike, Hagen, \& Sattler, 1986), a standardized test designed 
to assess general cognitive abilities, was administered yearly to children at ages 3 through 6 years. The Stanford-Binet, $4^{\text {th }}$ edition is standardized for use from ages 2 through 23 years. The scale scores can be used to obtain a Composite Standard Age Score (SAS) as well as subscale SAS scores for Verbal Reasoning, Abstract/Visual Reasoning, Quantitative Reasoning, and Short Term Memory. In all, there are 15 subtests, but the number of subtests administered varies according to the age and ability of the child. For this study, the same core subtests were administered to all children, namely, Vocabulary, Comprehension, Absurdities, Pattern Analysis, Copying, Quantitative, Bead Memory, and Memory for Sentences. The expected mean SAS score is $100(S D=16)$. The reported test-retest reliability (over a 2- to 8-month period) is .91 at 5 years for Composite SAS and to range from .56 to .78 for the subtests (Thorndike et al., 1986). For the purposes of this study, the Stanford-Binet, $4^{\text {th }}$ edition Composite SAS (CSAS), Verbal Reasoning Subscale SAS (VRSAS), Abstract/Visual Reasoning Subscale SAS (AVSAS), and the subtests that comprise these subscales were used.

\section{Procedure}

The children were tested at yearly intervals, with the data reported here including tests conducted at 3 through 6 years of age. Tests were administered to each child within 4 weeks of the child's birth date. Stanford-Binet, $4^{\text {th }}$ edition scales were administered in the laboratory during the child's yearly testing session. While the child was tested parents completed questionnaires that included information concerning parental education, occupation, and income. The HOME was administered during the home visit that was scheduled within 1 week of the laboratory testing session at age 3 years.

\section{Analysis}

Growth curve analyses were used to analyze the longitudinal data. Conceptually, these analyses can be considered to consist of two phases-an individual (within-subject) phase and a group (betweensubject) phase-although both phases actually are carried out simultaneously. To estimate the parameters of the within-subject model, individual growth curves were calculated by regressing the pertinent intelligence score on age (in years). These parameters can include linear, quadratic, and higher order terms (e.g., a cubic term), where the highest term order is constrained by the number of evaluations per participant. The indi- 
vidual growth curve for each child can be specified by the following model:

$$
Y_{i t}=\pi_{0 i}+\pi_{1 i}^{*} A_{i t}+\pi_{2 i} * A^{2}{ }_{i t}+R_{i t}
$$

where $Y_{i t}$ is the performance for child $i$ at time $t ; \pi_{0 i}$ is child $i^{\prime}$ s intercept parameter, which is the expected score for child $i$ when age equals $0 ; \pi_{1 i}$ is the slope of the line relating IQ to age for child $i$ (as such, $\pi_{1 i}$ describes the rate of change in performance when age equals 0$) ; A_{i t}$ is age for child $i$ at time $t ; \pi_{2 i}$ is the acceleration of the curve relating performance to age for child $i$ (as such, $\pi_{2 i}$ describes the acceleration of performance change at age equals 0$) ; A^{2}{ }_{i t}$ is the squared age for child $i$ at time $t$; and $R_{i t}$ is random error.

The intercept of the individual growth curve represents the child's expected performance when age is at 0 in the growth model. Consequently, intercept values and their variance depend on the age that has been arbitrarily set equal to 0 in the model. The zero point also is referred to as the centering point. The purpose of centering is to express the estimate of the particular growth parameter in a more meaningful manner. Centering is accomplished by simple subtraction, thereby shifting each score by the same amount. For example, if age in the analyses is uncentered, then the intercept value will be estimated when age equals 0 , literally estimating the intellectual performance of the child at birth. If estimating performance at birth is not relevant to the hypotheses under study, as is the case here, selecting a centering point permits a relevant investigation by uniformly shifting the zero point to a meaningful value. There is considerable flexibility in the choice of a centering point. The choice can be determined to be an age that is relevant to the study hypotheses. Statistically, it is helpful to choose a centering point inside the range of participant data so that the parameter estimates do not become unduly correlated. In the analyses reported here, age was centered at 3 years because it represented the age at which environmental information was gathered and the majority of the children had 3 -year evaluations. To center the data at age 3 years, the value 3 would be subtracted from each child's age. The uncentered sample mean age at the 3-year evaluation is 3.01 years; when centered, the mean becomes 0.01 (i.e., $3.01-3$ ). Centering does not change the process of estimating higher order growth parameters, such as slope or acceleration, but rather examines growth at different ages along the total growth trajectory (see Kreft, de Leeuw, \& Aiken, 1995, for a technical discussion and 
examples). The HOME and SES values at the $10^{\text {th }}$ percentile for the sample were used as the centering point for the independent variables (SES $=2$ and $\mathrm{HOME}=39$ ).

In the present study, hypotheses were examined using a mixed models approach with restricted maximum likelihood estimation. PROC MIXED from SAS version 6.12 was employed. Two sets of models were fit for statistical analysis: (a) Unconditional models were used to examine the mean and variance of the within-subject parameters, and (b) conditional models were estimated to account for the variance of the withinsubject parameters.

The unconditional models included an intercept representing the child's expected intellectual performance at 3 years of age, a slope parameter, and a quadratic term. In these models, the slope parameter represented the slope of the line that is tangent to the growth curve at age 3 years (i.e., the instantaneous rate of change at the centering point) when the quadratic term also is included in the model. For those models that only included a linear parameter, the slope reflects the linear rate of performance change across the observation period. The quadratic parameter described the rate of change in this slope parameter at the centered age (i.e., the quadratic parameter represented the extent to which the slope of the growth curve is increasing [a positive quadratic term] or decreasing [a negative quadratic parameter]). The parameters are estimated while controlling for all other parameters in the model.

From the individual curves and corresponding estimated parameters, aggregate group curves were derived and expressed in terms of betweenparticipant predictor variables (i.e., SES, HOME). The conditional models examined the influences of the predictor variables on the intercept, slope, and acceleration parameters and were fit by entering the predictors in a single block. To determine the optimal predictive model, both SES and HOME scores were entered to predict the intercept, linear slope, and acceleration terms. Nonsignificant predictors were eliminated by a backwards deletion procedure, starting with the highest order term and working back to the intercept. If an effect for a higher order term was significant, it was included in lower order terms, even if it was not significant, in order to improve estimability (e.g., if SES predicted the linear rate of change, it also was included as a predictor of the intercept regardless of the $p$ value).

For these analyses, growth trajectories first were calculated using the Stanford Binet, $4^{\text {th }}$ edition SAS scores in the standard score metric $(M=$ $100, S D=16$ ). First, the purpose of this paper was to examine differences in intellectual growth patterns related to environment measures, not to 
determine the specific shape or form that describes the manner by which children developmentally acquire intellectual skills (Burchinal \& Appelbaum, 1991). The standard score metric is most commonly used to describe children's intellectual abilities in educational, psychological, and medical settings, thereby increasing the generalizability of the study results. A similar approach has been used in childhood cancer survivors (Francis, Copeland, \& Moore, 1994), where the goal was to identify diagnostic variables associated with performance decline. The disadvantage of using standard scores in growth curve analysis is that the process of age standarization, while making score variance equal across age, sacrifices the underlying individual differences in growth. To accomplish variance stability with age, different transformations are utilized at each age in order to maintain constant population means and variances at all ages. Therefore, the raw scores for the five subtests that comprise the VRSAS and AVSAS subscales (Vocabulary, Comprehension, Absurdities, Pattern Analysis, and Copying) also were analyzed. Mental age scores were not used because the interval between scores at different ages is variable and unknown.

\section{RESULTS}

The means and standard deviations for the measures of the independent variables and age are depicted in Table 1. Table 2 depicts the mean SAS scores at each measurement occasion. Of the 105 children, 76 children had intelligence scores for all four measurement occasions, and 29 children had scores for three occasions. Among children without all four measurements, 4 children did not have scores at age 3 years, 6 children at age 4 years, 9 children at age 5 years, and 10 children at age 6 years. There were a total of 391 observations for the full sample. In Table 2, it is apparent that sample mean CSAS and AVSAS values declined between ages 4 and 5 years. These declines were greater than the Stanford-Binet, $4^{\text {th }}$ edition standard error of the measure of 2.8 points. The mean VRSAS score oscillated around a grand mean value of 105, with changes that exceeded the standard error of the measure at ages 3 to 4 years and again at ages 5 and 6 years. In Figures 1, 2, and 3, the respective CSAS, VRSAS, and AVSAS scores were plotted as a function of age for each of the 105 participants. Group CSAS and AVSAS performance visibly declined with age in Figure 1, although the decline was not stepwise as depicted by the group means in Table 2. In Figure 2, VRSAS scores were basically stable across age. 


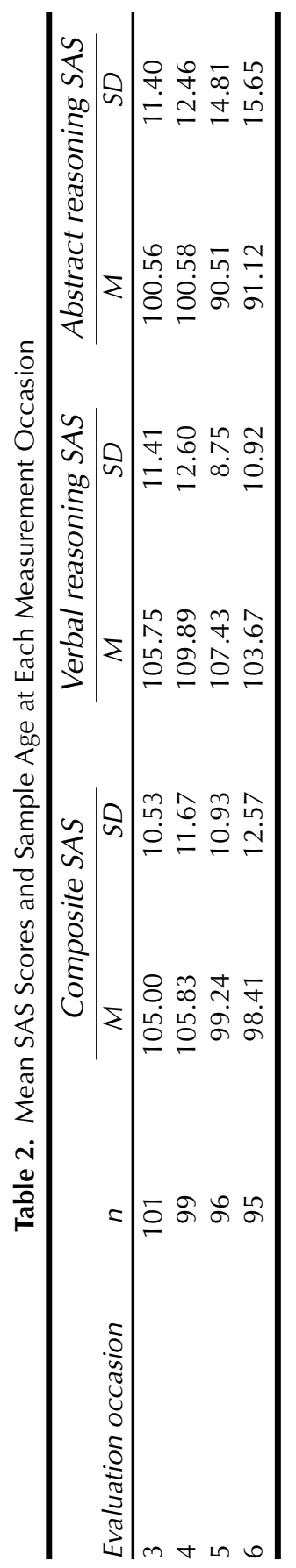




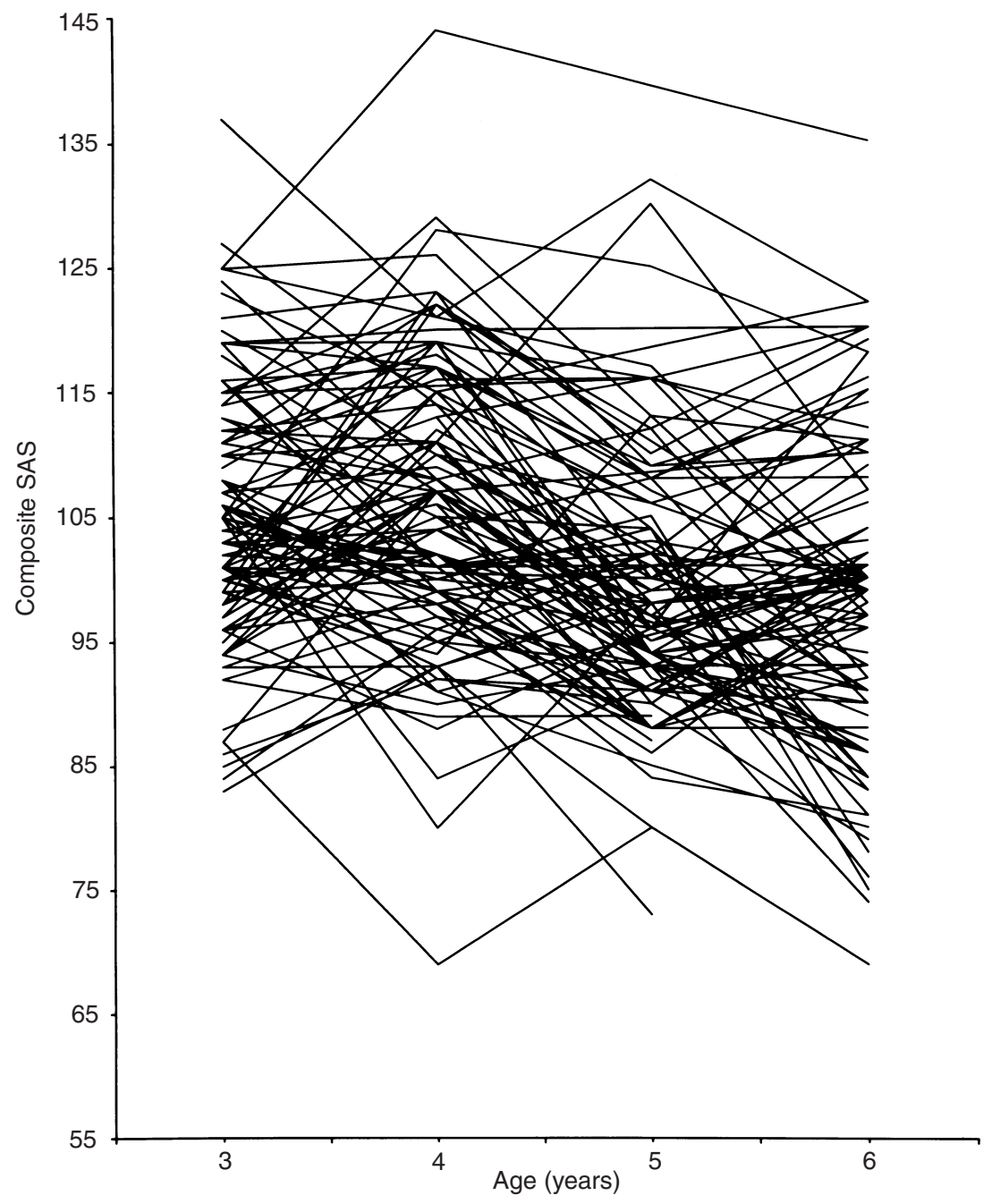

Figure 1. Growth trajectories of composite SAS scores as a function of age in months

\section{Unconditional Models: Examination of Within-Subject Parameters}

Results for the unconditional models are presented in Table 3. With the exception of the linear performance change in CSAS, all growth parameters differed statistically from zero. The expected CSAS score at 3 years of age was 105.60 points, representing performance of a typical 


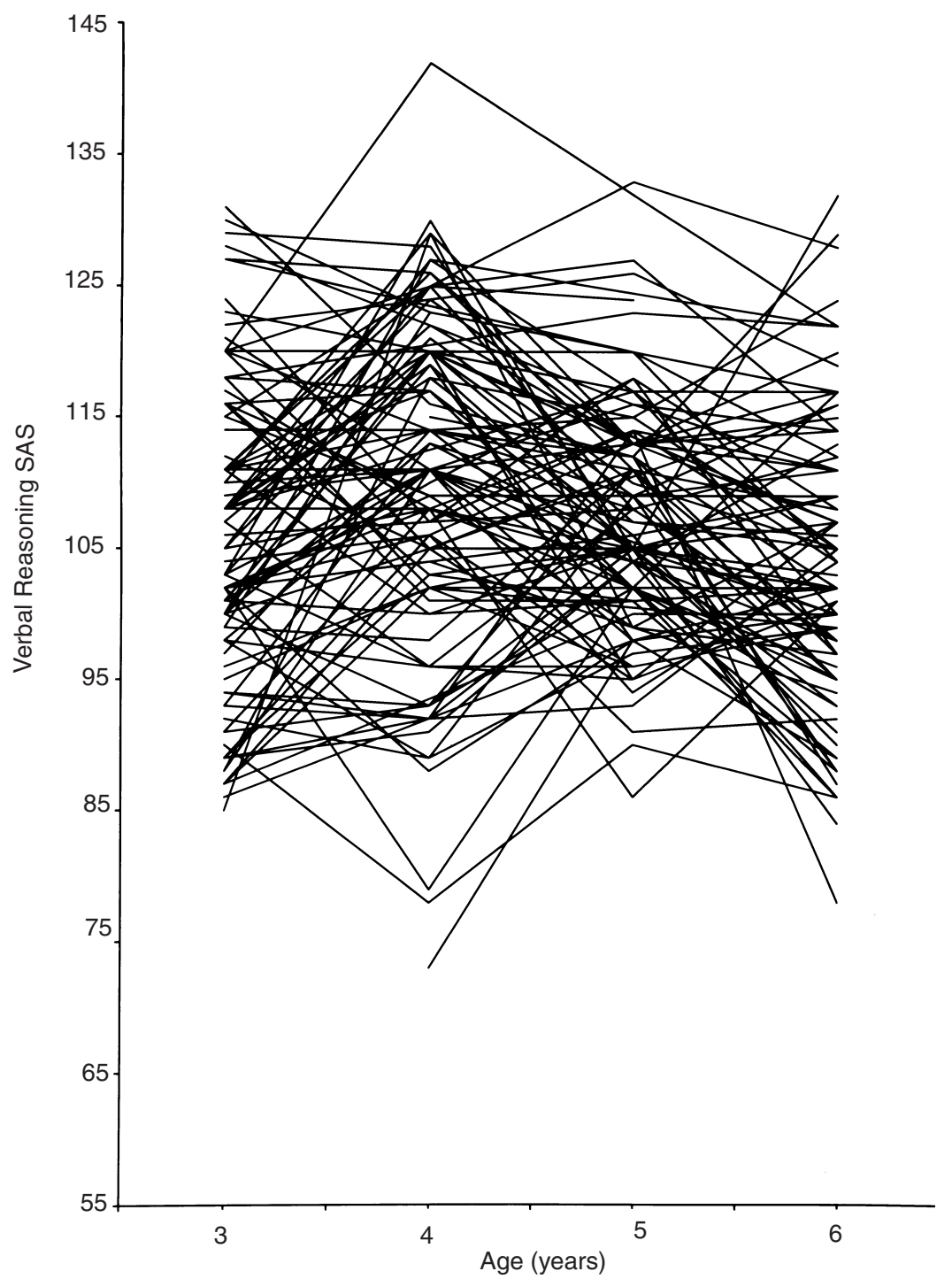

Figure 2. Growth trajectories of Verbal Reasoning composite SAS scores as a function of age in months 


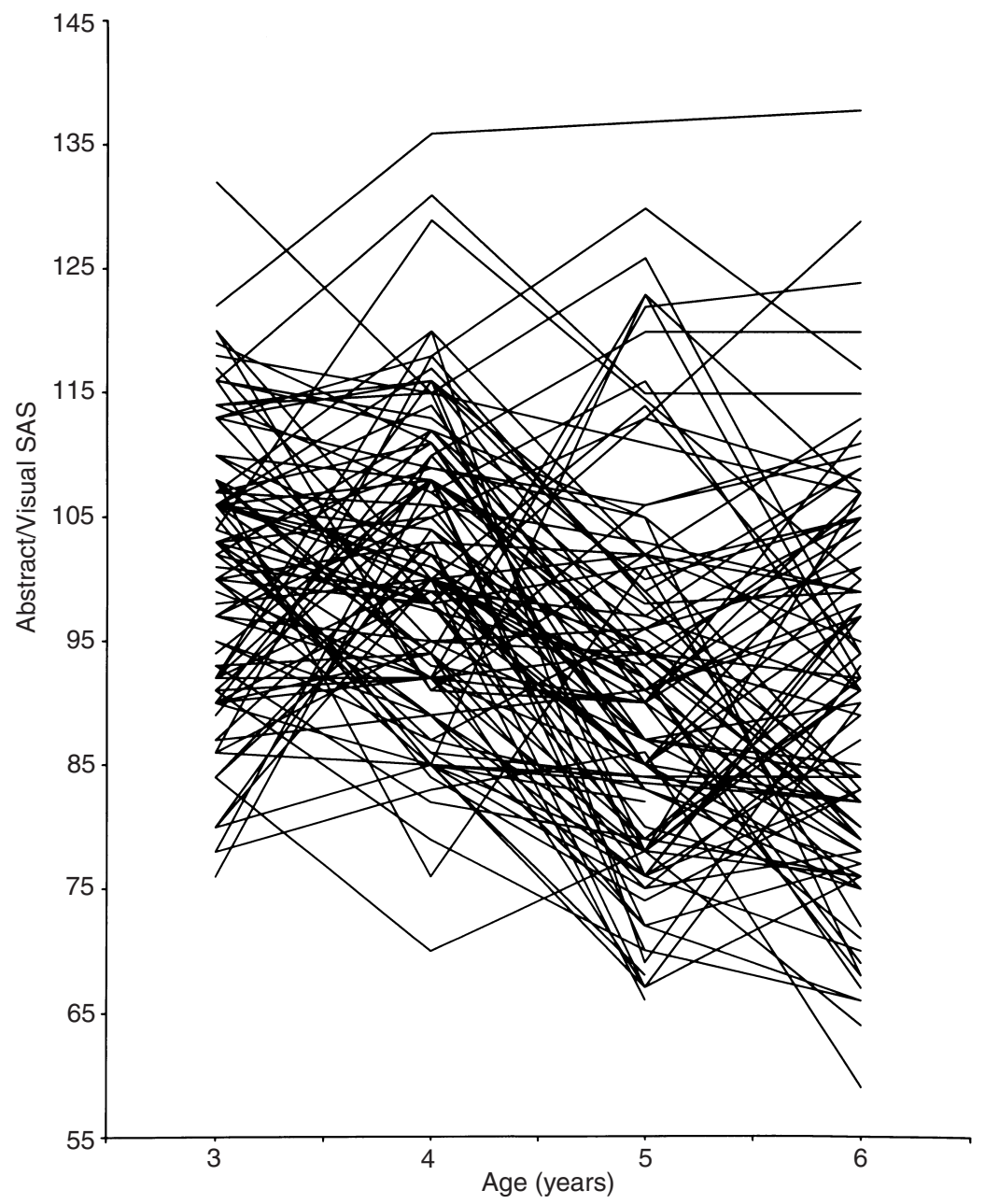

Figure 3. Growth trajectories of Abstract/Visual Reasoning composite SAS scores as a function of age in months

3-year-old child, independent of SES and HOME score status. Although nonsignificant, the mean slope parameter was -0.60 SAS points per year. At 3 years of age, the child would be expected to lose less than one SAS score point per year. The expected acceleration $\left(\pi_{2 i}=-0.74\right.$ IQ points per year) differed significantly from zero, indicating that the rate of growth in CSAS scores was not constant, but rather progressively declining. There was significant variability in the CSAS intercept and slope 


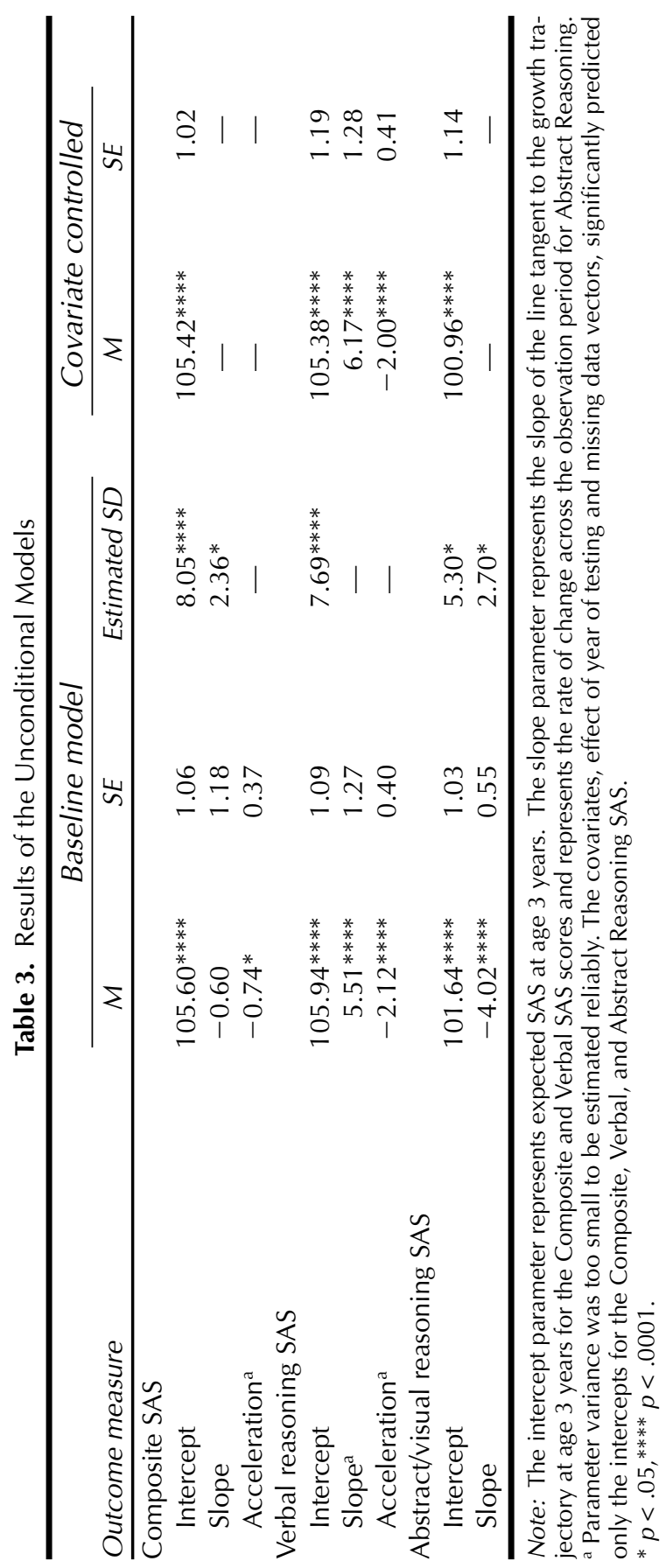


parameters, indicating that expected CSAS score and linear CSAS growth differed among children at 3 years of age. Expected CSAS and linear CSAS growth, then, was person-specific. The variability in acceleration of CSAS growth, however, was not statistically significant, indicating that the acceleration in CSAS growth was constant across individuals, where all children showed comparable quadratic CSAS score change.

A model that included intercept, linear, and quadratic terms also best described the VRSAS scores. An average child was expected to obtain a VRSAS score of 105.94, with substantial linear growth (5.51 SAS points per year) but attenuating acceleration over the observation period $(-2.12$ points per year). Unlike the results for CSAS, there was significant variability only in the intercept parameter, meaning that individual children differed only in the expected VRSAS score at age 3 years. A cubic model also was examined because of the oscillating pattern of means, despite limitations in power to detect such an effect with only a maximal of four measurement occasions per child. The cubic term was not significant $(p>.15)$, and therefore this model was rejected. It is possible that a cubic model may have adequately fit the data if there were more measurement occasions. The significant linear and quadratic VRSAS growth parameters likely represented natural or error variability around a grand mean, consistent with a constant pattern of score change depicted in Figure 2 and Table 2.

For AVSAS, a linear model best fit the data. The average child at age 3 years would score 101.64 points, regardless of SES and HOME scores. Across the observation period, there was significant linear change in the AVSAS score, -4.02 points per year. Significant variability occurred in both the intercept and linear slope parameters, indicating that children varied in their AVSAS score at age 3 years and in their linear rate of change with age.

Because of the unexpected pattern of development in the SAS scores, a series of analyses were undertaken to further investigate the pattern of change. ${ }^{1}$ One possible source of variability in patterns of developmental

${ }^{1}$ The Stanford-Binet, $4^{\text {th }}$ edition uses a scoring procedure whereby if a child scores a 0 on a particular subtest, performance on this subtest is not used to calculate the pertinent subscale SAS score. For example, if a child obtained a 0 on the Absurdities subtest, the VRSAS score is calculated on the basis of administration of only two subtests, in this case, Vocabulary and Comprehension. For the purposes of this analysis, one SAS score point was subtracted from the lowest available SAS score (Raw Score $=1$ ) and substituted for all subtests where a score of 0 was obtained. For example, if a raw score of 1 received a SAS of 39, then a raw score of 0 was rescaled to yield SAS score of 38 . Therefore, all children received a SAS score on all the core subtests. The next lowest SAS value was chosen for re-scaling as a conservative method to allow the child the "best" possible score. The results from these analyses did not yield substantively different findings. The decline in CSAS and AVSAS scores was of similar magnitude, and the oscillating pattern was observed for the VRSAS scores. These results are available from the first author for interested readers. 
change is differential attrition. Often in longitudinal samples, the highest risk children, in this case those children from the lowest SES/HOME environment scores, are more difficult to retain in the sample across time. In this sample, the range of environmental disadvantage is more restricted than what is found in urban samples where differential attrition is routinely encountered. If families from more disadvantaged environments drop out progressively with age, mean sample IQ would change as a function of those children of lower SES dropping out of the study prematurely. Although in the present study CSAS scores actually declined with age, the pattern of missing data was investigated to determine whether the mechanism of missing data was consistent with the missing at random assumption. If this assumption is met, then the mechanism of missing data are said to be ignorable; that is, it does not substantively adversely affect the results. Groups were formed consisting of those children at each age who had CSAS scores versus those who did not (e.g., at age 3 years, the 101 children with CSAS scores made up the "evaluated" group and the 4 children without CSAS scores comprised the comparison "missing group"). CSAS scores then were compared by $t$ tests between these two groups at all other ages. If the $t$ test was significant, then testing at one age was dependent upon testing at another, inconsistent with the missing at random assumption. There were $12 t$-test comparisons for the CSAS scores and 4 comparisons each for SES and HOME scores. Three of these tests yielded significant differences: Children who were not tested at age 4 years had higher SES $(M=5.85 ; S D=1.23)$ than those who were $(M$ $=4.51 ; S D=1.14$ ); children who were not evaluated at age 6 years had a lower mean CSAS score $(M=99.40 ; S D=9.07)$ than those who were $(M=106.55 ; S D=11.74)$ at ages 4 and 5 years $(M$ not evaluated $=$ 91.20, $S D=10.49 ; M$ evaluated $=100.17, S D=10.15)$. Because these tests lack power due to the small number of children with missing evaluations, the direction of mean differences was examined. Results indicated that missing data that occurred at early ages ( 3 to 5 years of age) yielded differences in the CSAS score such that children who were not evaluated outscored by 4 to 7 points those children who were. For missing data at age 6 years, the children who were evaluated obtained higher CSAS scores than those children with missing data by 7 to 9 points. Therefore, missing data were dummy coded $(1=$ missing; $0=$ obtained $)$ with four vectors representing each of the evaluation ages and were controlled on all subsequent analyses.

The effect of evaluation year also was examined. In this ongoing longitudinal study, different testers administered the Stanford-Binet, $4^{\text {th }}$ edition during different periods of the project, without concurrent starting and ending dates. However, when there were new lab personnel, their 
duties and training started at the beginning of the academic year. Therefore, the year of test administration was examined. Preliminary analyses of variance (ANOVAs) indicated differences in mean CSAS and AVSAS scores between children who were tested during or before 1991 and those tested after. There were few significant differences among administration years for the VRSAS scores, and of those that differed, a clear pattern was not apparent. Yearly differences in CSAS and AVSAS scores ranged from 5 to 10 points, whereas differences in VRSAS scores varied from 0.5 to 7 points. Therefore, a dichotomous variable was created (0 represented evaluation during or before 1991, 1 represented administration during or after 1992) and entered as a control variable on all subsequent analyses.

In Table 3, the unconditional model results are presented after controlling for testing year and missing data. The CSAS slope and acceleration parameters were no longer significant after these covariates were included in the model. These results indicate that the expected score for a child at any age is the intercept value, 105.42. A similar result was obtained for AVSAS scores, with a typical child of any age expected to obtain an AVSAS score of 100.96. With testing year and missing data controlled, the rate of change in AVSAS scores was nonsignificant. Interestingly, no substantive change occurred in the analyses of VRSAS score development when year of testing and missing data were entered as covariates in the model. VRSAS scores continued to be described best by a quadratic model, with a positive slope and decreasing acceleration at age 3 years. Despite the lack of significant effects, year of testing and missing data were controlled on all remaining analyses to remove any variability that was attributable to these effects.

\section{Conditional Models: Correlates of Within-Subject Parameters}

The effects of SES and HOME scores on changes in intellectual skills were examined despite nonsignificant individual variability in the growth parameters for CSAS and AVSAS scores for two reasons. First, the tests for parameter variance are inherently conservative; therefore, there may be undetected individual variability (Hunter \& Schmidt, 1990). Second, visual inspection of Figures 1, 2, and 3 reveals a significant portion of children with differing growth profiles, although the overall plot is relatively flat. These differential profiles may be related to the predictors of interest; therefore, these analyses were conducted on all three SAS scores.

Composite SAS. The effects of SES and HOME on the change in CSAS, VRSAS, and AVSAS scores are depicted in Table 4. Both SES and HOME scores predicted the expected CSAS at 3 years of age. The 


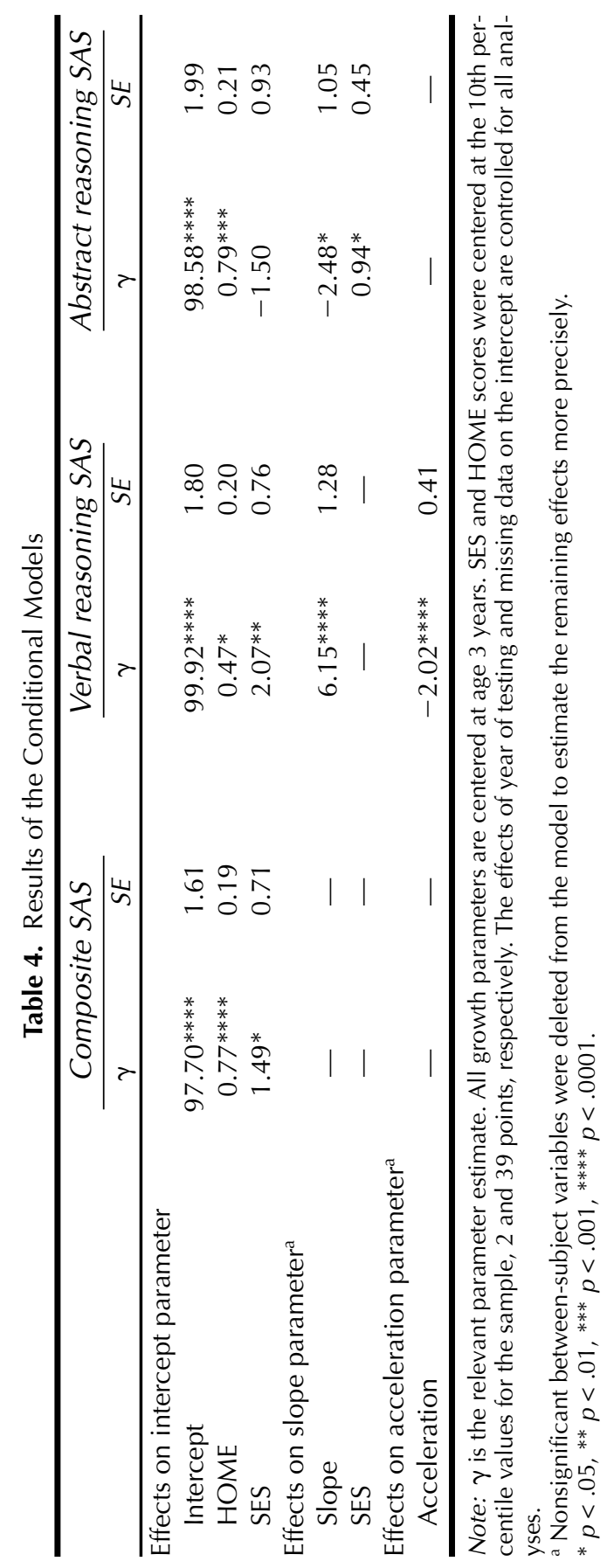


expected CSAS score, when SES and HOME were equal to 0 (centered as 2 and 39 points, or $10^{\text {th }}$ percentile values of the sample, respectively), was 97.70 points at 3 years of age. The CSAS score was 1.49 points higher for each SES score point (above the centered value of 2). Each additional HOME score point was associated with a higher CSAS score of 0.77 points. Therefore, at 3 years of age, a child whose family received an SES score of 5 would be expected to obtain a CSAS score of 102.17 (97.70 + [3 SES points * 1.49]). Correspondingly, a 3-year-old child with a HOME score of 44 would be expected to obtain an IQ of 101.55 (97.70 + [5 HOME score points * 0.77]). Neither SES nor HOME scores predicted the linear or quadratic rates of change in CSAS scores. This result indicated that SES and HOME each affected the level of CSAS performance at age 3 years, and that the magnitudes of these effects were constant across the developmental period studied here. The conditional model, that is, including HOME and SES scores to predict the intercept parameter, accounted for $31.50 \%$ of the explainable variability in the growth model. This value differs from traditional $R^{2}$ statistics and should not be interpreted identically (see Snijders \& Bosker, 1994, for a discussion of limitations).

Verbal Reasoning Subscale SAS. Both SES and HOME scores predicted the expected VRSAS score at 3 years of age. At centered SES and HOME score values, the expected VRSAS score was 99.92 points. The effect of SES on the VRSAS score was 2.07 points, whereas each HOME score point was associated with a 0.47 difference in VRSAS. Although there was significant linear and quadratic change in the VRSAS score, SES and HOME scores did not predict either of these growth parameters. This conditional model accounted for $21.62 \%$ of the explainable variability in the growth model. Similar to those for CSAS, these results indicated that the child's environment affected the level of verbal intellectual performance at age 3 years, with no differential effects across age.

Abstract/Visual Reasoning Subscale SAS. Unlike results for CSAS and VRSAS scores, only HOME score significantly predicted the AVSAS intercept. At the centered values of HOME and SES, the expected AVSAS score was 98.58. A one-point difference in HOME score was related to a 0.79 difference in expected AVSAS score. Interestingly, SES scores predicted the linear rate of change in AVSAS scores, but not the intercept. For AVSAS, the average rate of change was negative, meaning that scores declined with age by 2.48 points per year. The effect of SES was to attenuate this rate of decline at moderate SES values (values < 4.5). Children with higher SES values showed constant or marginally increasing performance with age. This conditional model accounted for $38.87 \%$ of the explainable variability in the growth model. These results indicated that 
the HOME score influenced the level of nonverbal intellectual performance at age 3 years, in a constant manner across the age span studied here. Differences in AVSAS scores related to SES at age 3 years were minimal, however developmentally, nonverbal intellectual performance differentiated among children of differing SES, such that the more disadvantaged showed larger performance declines relative to higher SES children.

These statistical effects are depicted graphically in Figures 4, 5, and 6, where the respective predicted CSAS, VRSAS, and AVSAS scores are plotted across age as a function of SES group membership. SES group membership was defined on the basis of using a cut score of one standard deviation below (Low Group) or above (High Group) the sample mean SES score. For the CSAS score, the SES group differences, apparent at age 3 years, were stable across the age span. For VRSAS, although the developmental performance trajectories of the High and Medium SES groups were similar, the difference between these children and those classified as Low was stable across development. A different picture emerged for the AVSAS. Initially at

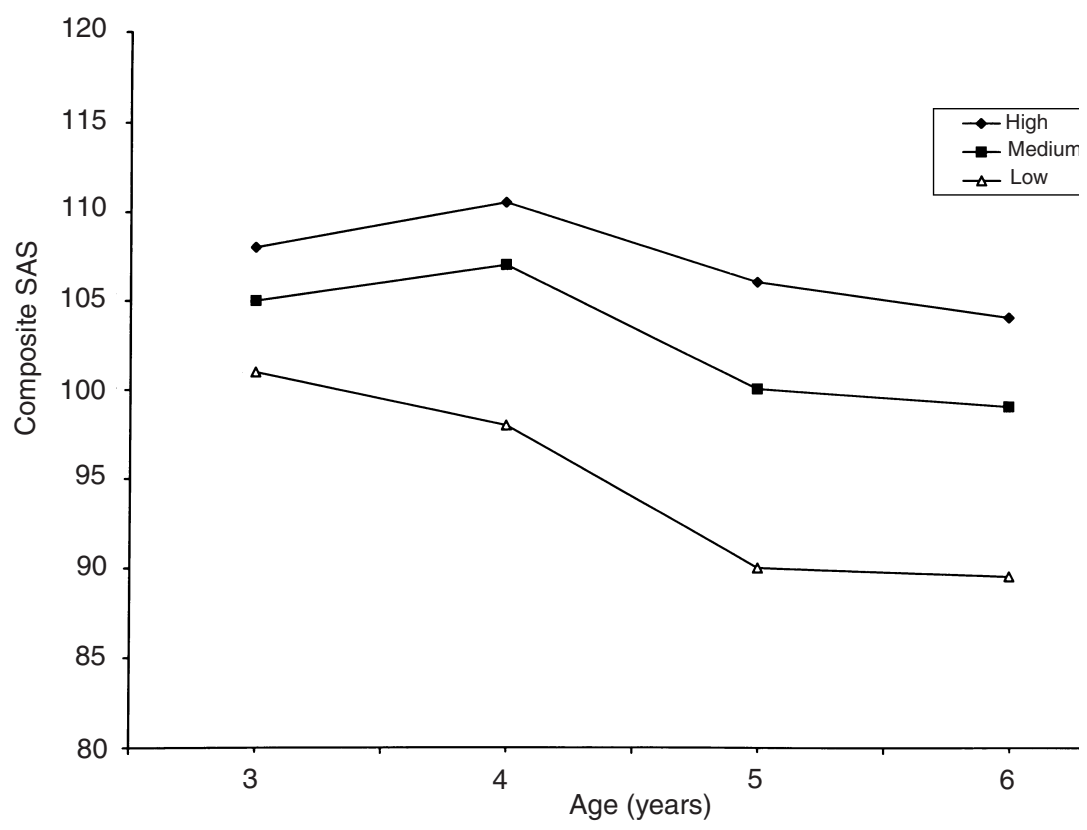

Figure 4. Growth trajectories of the predicted composite SAS scores as a function of age in years and SES group. High $=1 \mathrm{SD}$ above the sample mean SES, Med $=$ within $1 \mathrm{SD}$ of the sample mean SES, Low = less than $1 \mathrm{SD}$ of the sample mean SES. 


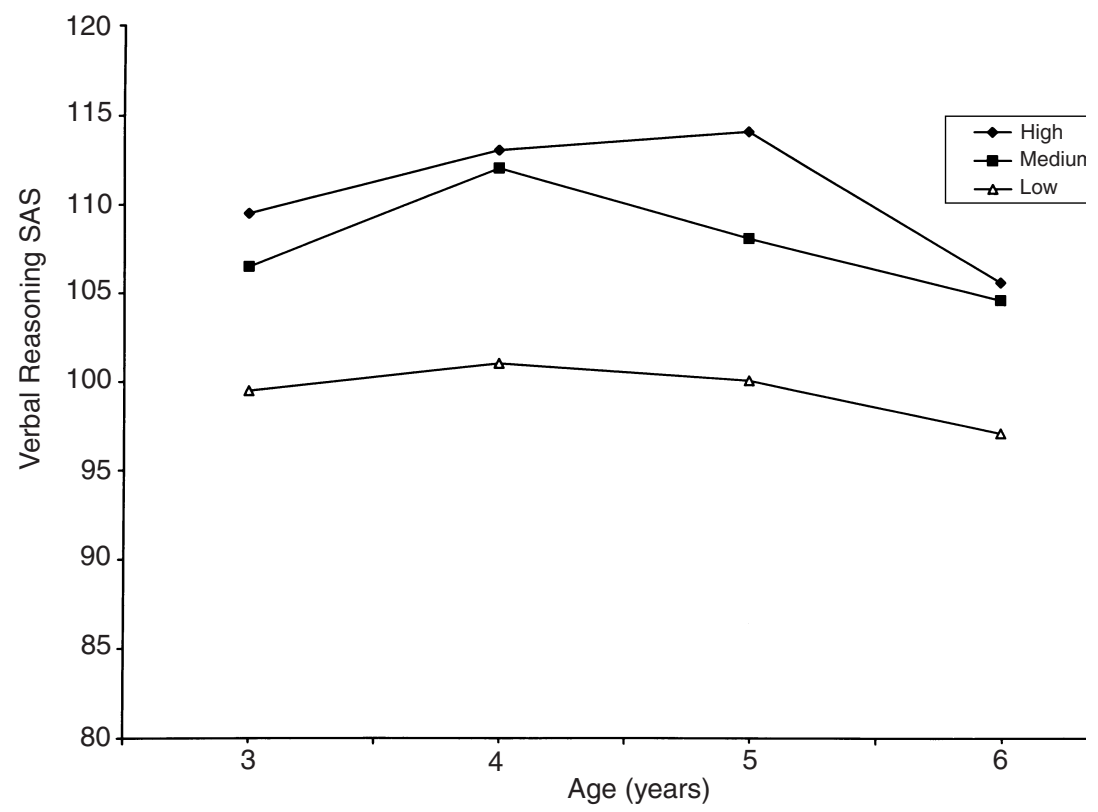

Figure 5. Growth trajectories of the predicted Verbal Reasoning SAS scores as a function of age in years and SES group. High $=1 \mathrm{SD}$ above the sample mean SES, Med = within $1 \mathrm{SD}$ of the sample mean SES, Low = less than $1 \mathrm{SD}$ of the sample mean SES.

age 3 years, the difference between SES groups was negligible. With advancing age, the AVSAS performance of the groups separated, such that those children of lower SES progressively lost ground relative to those children of higher SES, who showed a more stable pattern of performance.

\section{Subtest Raw Score Analyses}

Because standard scores are transformed statistically to have equivalent variance at each age, it may be that the environmental effects found are artifacts of this transformation process. Therefore, similar analyses were performed on the raw scores from subtests that comprised the VRSAS and AVSAS Subscales (Vocabulary, Comprehension, Absurdities, Pattern Analysis, and Copying). As for the standard score analyses, the effects of testing year and missing data were controlled statistically. The results from the unconditional models are presented in Table 5. The pattern of development for Vocabulary, Absurdities, and Pattern Analysis subtests was quadratic, with the VRSAS subtests exhibiting an increasing 


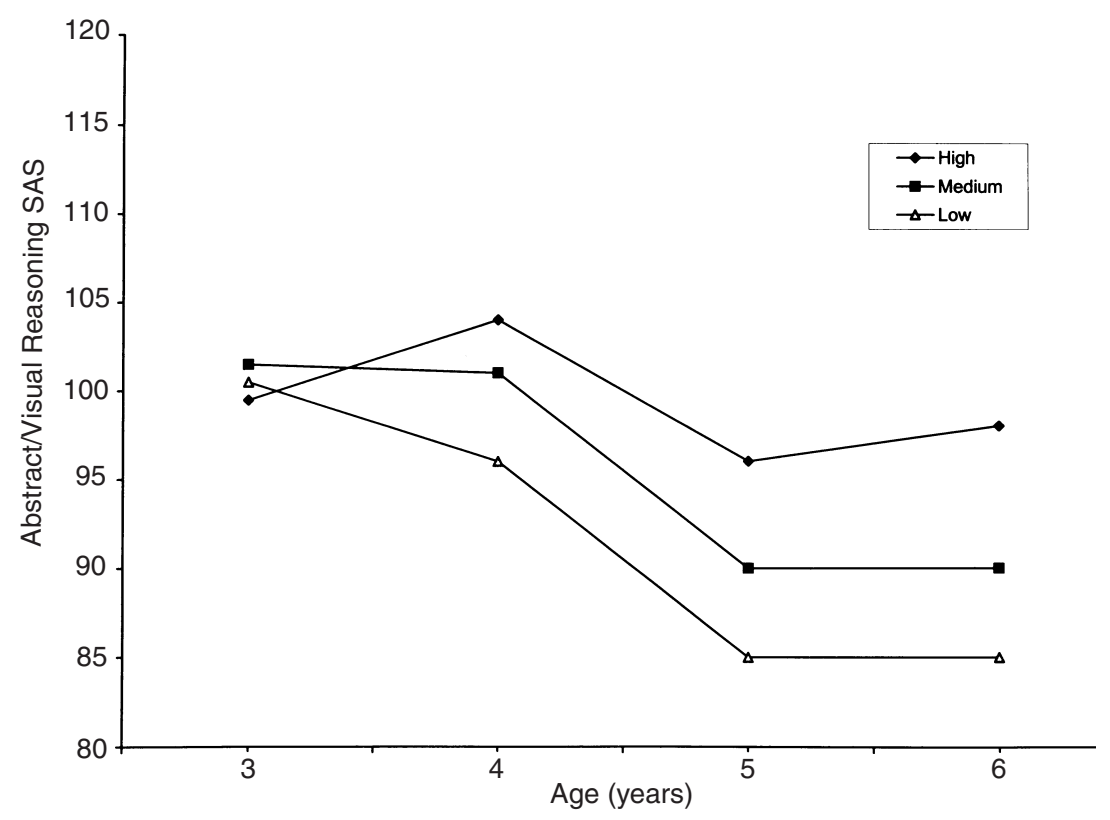

Figure 6. Growth trajectories of the predicted Abstract/Visual SAS scores as a function of age in years and SES group. High $=1 \mathrm{SD}$ above the sample mean SES, Med = within $1 \mathrm{SD}$ of the sample mean SES, Low = less than $1 \mathrm{SD}$ of the sample mean SES.

but subsiding (negative acceleration) pattern and the Pattern Analysis consistent with an increasing and accelerating pattern of growth (positive acceleration). Growth on the Comprehension and Copying subtests was linear and positive in slope. Performance at age 3 years on all subtests was person-specific; that is, there was significant variability in the intercept parameters for all subtest raw scores. However, variability in developmental growth was found only for linear change in Vocabulary raw scores.

Table 6 contains the results of the conditional models. SES and HOME scores were included as predictors of the growth parameters, regardless of whether there were individual differences in the parameter values, in order to compare results from analysis of the SAS scores. For VRSAS subtests, SES predicted the Vocabulary raw score at age 3 years, whereas HOME score predicted performance on the Absurdities subtest. Neither SES nor HOME scores predicted the linear or quadratic rates of raw score performance change for any of the VRSAS subtests. For the Comprehension subtest, the child's environment did not predict any of 
Table 5. Results of the Unconditional Models for Subtest Raw Scores

\begin{tabular}{|c|c|c|c|}
\hline Subtest raw score & $M$ & $S E$ & Estimated SD \\
\hline \multicolumn{4}{|l|}{ Vocabulary } \\
\hline Intercept & $10.17^{* * * *}$ & 0.37 & $2.67^{* * * *}$ \\
\hline Slope & $4.52^{* * * *}$ & 0.37 & $0.87^{* *}$ \\
\hline Acceleration $^{\mathrm{a}}$ & $-0.52^{* * * *}$ & 0.12 & - \\
\hline \multicolumn{4}{|l|}{ Comprehension } \\
\hline Intercept & $8.37^{* * * * *}$ & 0.42 & $1.51 *$ \\
\hline Slope $^{\mathrm{a}}$ & $3.63^{* * * *}$ & 0.26 & - \\
\hline \multicolumn{4}{|l|}{ Absurdities } \\
\hline Intercept & $5.04 * * * *$ & 0.48 & $2.09 * * *$ \\
\hline Slope & $7.45^{* * * *}$ & 0.64 & - \\
\hline Acceleration $^{\mathrm{a}}$ & $-1.11 * * * *$ & 0.21 & - \\
\hline \multicolumn{4}{|l|}{ Pattern analysis } \\
\hline Intercept & $6.64 * * * *$ & 0.42 & $1.73^{*}$ \\
\hline Slope ${ }^{a}$ & $2.31^{* * * *}$ & 0.58 & - \\
\hline Acceleration & $0.48^{* *}$ & 0.18 & - \\
\hline \multicolumn{4}{|l|}{ Copying } \\
\hline Intercept & $2.48^{* * * *}$ & 0.34 & $1.42^{* * * *}$ \\
\hline Slope $\mathrm{a}^{\mathrm{a}}$ & $3.51 * * * *$ & 0.21 & - \\
\hline
\end{tabular}

Note: The intercept parameter is the expected subtest raw score at age 3. The slope parameter represents the slope of the line tangent to the growth trajectory at age 3 for quadratic models and the slope is the rate of change over the observation period for linear models. The effects of testing year and missing data on the intercept are controlled for all analyses.

a Parameter variance was too small to be estimated reliably.

$* p<.05,{ }^{* *} p<.01 ; * * * *<.0001$.

the growth parameters. These raw score results provided confirmation that the child's environment predicted the level of verbal intellectual skills at age 3 years. Also consistent with the VRSAS results, the effect of the child's environment on the verbal subtest raw scores was constant across age.

For the nonverbal AVSAS subtests, SES significantly predicted linear growth for the Copying subtest raw score. SES and HOME scores were related to the expected Copying raw score at age 3 years. The effect of SES on the expected Copying raw score was negative in sign, indicating that children of higher SES performed more poorly than those of lower SES at age 3 years. This counterintuitive finding is consistent with the graphical depiction of AVSAS performance at age 3 years in Figure 3, most likely representing an artifact of the tightly clustered performance at this age among children of differing SES scores. Neither SES nor HOME scores predicted any of the growth parameters for the Pattern Analysis 


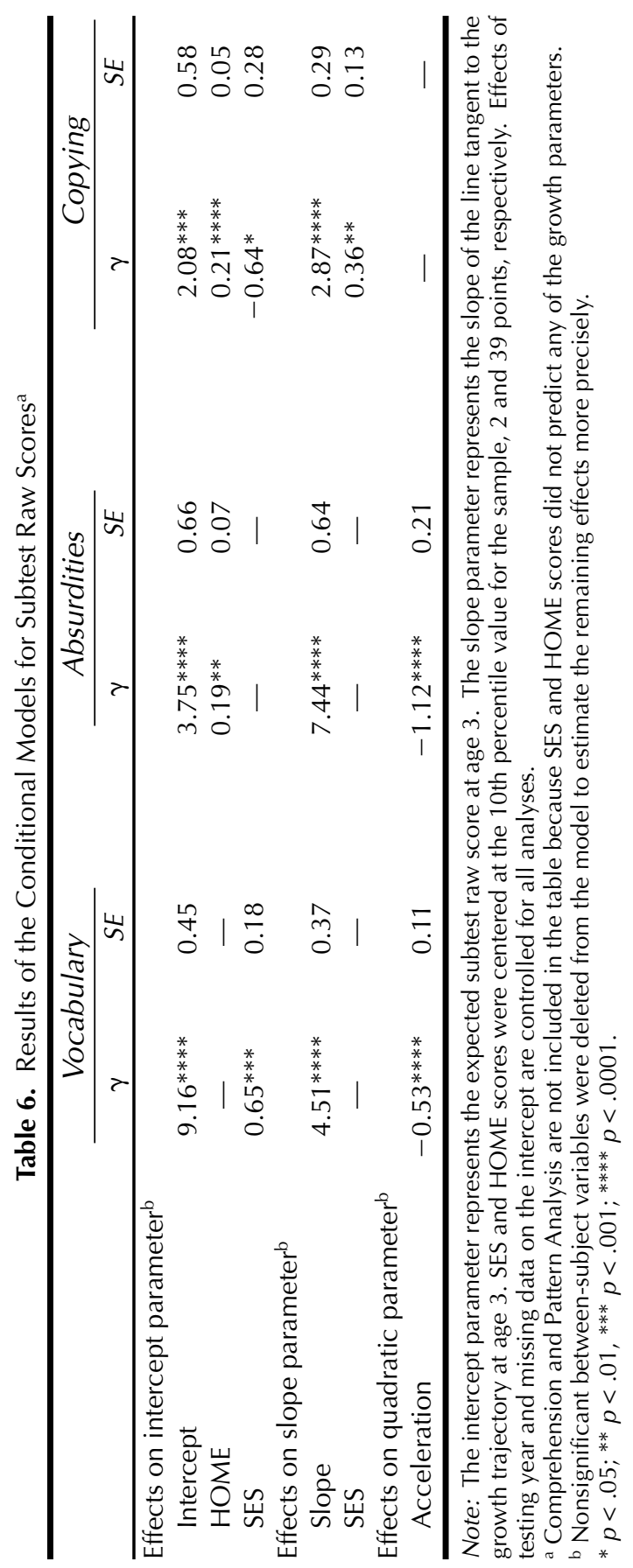


raw score. These raw score results also are consistent with those using AVSAS scores, where HOME and SES had differing effects on nonverbal intellectual skill development. HOME scores affected the level of raw score performance at age 3 years, with a constant effect across age. SES, in contrast, impacted the rate of development such that nonverbal intellectual subtest raw scores grew at a faster rate among children from higher SES families.

\section{DISCUSSION}

Several results emerged from the growth curve analyses in this study. First, the present study confirmed the results of previous analyses of this longitudinal data set and findings of other investigators (Gottfried, 1984; Gottfried \& Gottfried, 1984) that both HOME and SES influence the intelligence scores of children between the ages of 3 and 6 years. Although most previous investigations have concentrated on the infancy through early preschool years, the present study extends the findings to children through 6 years of age. In the present study, HOME scores exerted a constant influence on the expected composite, verbal, and nonverbal intellectual skills at each age point; that is, HOME scores were a stable predictor of early intellectual performance. Only early SES influenced the rate of intellectual growth, specifically for nonverbal intellectual skills. SES, which is more commonly used as a measure of home environment but which is a less direct measure than the HOME score, was an ongoing influence on intellectual abilities. The magnitudes of these environmental effects were moderate, yet consistent, regardless of whether agestandardized or subscale raw scores were analyzed. Consistent with the conclusions of Bradley, Caldwell, and Elardo (1977) and Gottfried and Gottfried (1984), HOME and SES are more than just different types of measures of the child's environment, because both variables had differential effects on children's intellectual growth patterns.

Second, these two indices of the child's environment influenced intellectual development in interesting ways. Children differing in $\mathrm{HOME}$ scores also differed in their intelligence scores, but the effects of HOME scores on intelligence remained constant across age. In the present study, however, the HOME scores were obtained only at one point in time (age 3 years). Had they been available at another age or ages within the range under study here, the result might have differed. Interestingly, there are no published studies reporting changes in HOME scores across the ages used in the present study. Gottfried (1984) reported on the stability of HOME scores obtained in the infancy and preschool ages (comparing between 
the Infant and Preschool versions of the HOME) across intervals ranging from 6 months to 4 years. The average stability coefficient was .50 (ranging from .42 to .58) across studies. Given the stable, rural, middle-class demographics of this study sample, the stability in HOME scores across a 3 -year age span where the same Preschool version of the HOME was used would be expected to be at least .50 as reported by Gottfried.

The influence of SES on intellectual development differed for verbal and nonverbal intelligence. For both the composite and verbal intelligence scores, SES was similar to HOME scores in influencing initial performance at age 3 years. Environment did not influence change rates, therefore, indicating a constant effect of environment across age. However, for nonverbal intelligence scores, initial SES influenced the amount of age-related change. Lower SES children failed to keep up with likeaged peers in nonverbal skill development, whereas small positive gains in nonverbal performance were observed in higher SES children. In this study, SES deleteriously and progressively impacted nonverbal intellectual skills in disadvantaged children relative to their peers during young childhood, but it buffered more advantaged children. Because nonverbal skills play a role in primary grade school achievement, these findings suggest one potential developmental pathway to early academic difficulties in children of lower SES.

This finding also is interesting in light of the presumed effects on intelligence tests of Flynn's findings of environmental influences across generations (Flynn, 1987). The finding that intelligence scores increased across generations led many scale developers to publish new editions of their tests with updated norms. Flynn reported the greatest environmental effects on tests of fluid intelligence (i.e., analytic abilities) rather than crystallized intelligence (i.e., learned or acquired abilities). The findings of the present study generally are consistent with the more potent effects of environmental influences on fluid intelligence scores, as measured by the Abstract/Visual Reasoning Subscale, even on the renormed StanfordBinet, $4^{\text {th }}$ edition.

These findings should be interpreted within design limitations. It would have been preferable to examine the longitudinal effects of the child's environment on intellectual development during this developmental period; that is, using SES and HOME scores (measured at each age) as time-varying covariates. Although SES information was collected annually, a single HOME observation was conducted at age 3 years for children in this age range due to the high personnel costs to conduct repeated home visits. The intercorrelations of SES scores measured at ages 3 to 6 years were quite stable (all $r s>.90$ ), consistent with the rural nature of the sample where opportunities for economic change are lim- 
ited. Interestingly, there were significant mean differences in SES at each adjacent age from ages 3 through 5 years (age 3 versus age $4, F[1,104]$ $=11.77, p<.001$; age 4 versus age 5 years, $F[1,104]=12.28, p<.001)$ but comparable mean SES levels at ages 5 and 6 years $(F[1,104]=.78$, $p>$.37). However, these mean SES differences at adjacent ages were relatively small (age 3 year $M=3.58$, age 4 year $M=3.64$, age 5 year $M=$ 3.81 , age 6 year $M=3.84$ ). When considered in the context of the study findings, these changes may account for the age lagged influence (i.e., effect on developmental rate) of SES on nonverbal intellectual development. Alternatively, SES may act as a "trait" variable, influencing nonverbal intellectual development at ages distal from the measurement occasion. Unfortunately, differences across age in HOME scores in this age range using the same version of the HOME were not available.

These effects are especially noteworthy given the stable, rural, largely middle-class sample relative to the more commonly studied, disadvantaged urban samples. These findings point to the importance of how the environment is characterized in seeking to understand the influence of environment on intellectual development in childhood for children living in different settings. The findings confirm the published reports by Gottfried (1984) that SES makes a separate and strong contribution to intellectual growth compared with other measures of home environment, including HOME scores.

Many of the more recent conceptualizations of intelligence focus on separating the different types of intellectual abilities that are frequently subsumed under a common term, "intelligence." Conceptualizations by Sternberg (1997), Gardner (1999), and Horn (1989) were developed to broaden the abilities considered to be important for intellectual functioning in different settings. Conceptualizations of "multiple" intellectual abilities fits in well with the growing understanding that the child's environment is "multilayered" as well. Reported here is one attempt to address how intellectual growth, when simply conceptualized as verbal and nonverbal, is influenced by an environment in which transactional relations between the child and different experiential factors in his/her environment are critical. The child's abilities and behaviors interact with and are affected by the people and experiences available in the environment. This notion of multilayered environmental influences is fundamental to behavior genetics studies on intelligence. For example, parents share both genes and environments for intelligence with their children, and thus a genotype-environment correlation exists within families (Plomin, DeFries, \& Loehlin, 1977; Scarr \& McCartney, 1983). Gottesman and colleagues (Gottesman, 1974; Turkheimer, Goldsmith, \& Gottesman, 1995) have suggested the concept of a "reaction range" that might help 
describe the relation between home environment and intelligence. The environment may be thought of as an expression of parental phenotype whose dynamic and potential for growth is influenced by parental genotype. Better educated parents may not only pass along their intelligence genotypes that influence the intellectual potential of their children, but they also may contribute less restrictive environments from which their children may obtain greater benefit. Children of less well-educated parents may have more restrictive environments as well as more restricted genotypes for intelligence, which may limit the benefits they can gain from the rearing environment. The present findings suggest more malleability or reactivity with age for nonverbal intellectual skills, such that the distal role of early SES at age 3 years has continued developmental impact, at least until age 6 years. In addition, the importance of SES and home environment in setting initial level of intellectual performance was demonstrated.

These findings may reflect some aspects of a gene-environment interaction. In this particular sample of rural, largely middle-class families, the expectation is that little in the family environment would contribute to changes in child intelligence with age (Scarr, 1992), as long as parents are able to meet the basic needs of their children. However, when SES is particularly low, as it is in the "Low SES" families reported here, then those basic needs may not be met and performance in these children would be expected to fall with age, relative to their peers. Additionally, Rowe, Jacobson, and Van den Oord (1999) found that shared environment explained a greater proportion of the variance for verbal IQ scores for children with less educated parents than for those with better educated parents. They surmised that this effect resulted from the restricted range of environmental influences in the less educated families causing children's innate abilities to be less fully expressed. Therefore, the shared environment was a more important influence on children's verbal intelligence. Unfortunately, Rowe et al. did not include other measures of IQ, so the nature of these effects may have differed if nonverbal IQ was examined, for example. In the present study, children from lower SES homes scored noticeably poorer on verbal IQ indices, whereas children from moderate to high SES homes largely were not distinguishable. Furthermore, nonverbal intelligence scores declined with age for children from low SES families, but remained relatively stable in children from higher SES families. These findings suggest that shared environment as measured by parental SES is more important for children in less advantaged environmental circumstances.

Although the differential influence of home environment and SES measures on intellectual outcomes at specific ages have been reported 
previously, the influence of these variables on the rate of intellectual growth in individuals has not been studied. In the present study, HOME scores exerted a constant influence on intelligence across the age range studied, whereas SES had a significant influence on growth rate of nonverbal intellectual skills. The fact that different environmental factors affected intellectual growth in different ways is intriguing and supports the importance of continuing further study on the relative impact of various environmental influences.

\section{REFERENCES}

AYLWARD, G. (1988). Infant and early childhood assessment. In M. Tramontana \& S. Hooper (Eds.), Assessment issues in clinical neuropsychology. New York: Plenum.

BONJEAN, C., HILL, R., \& MCLEMORE, S. (1967). Sociological measures: An inventory of scales and indices. San Francisco: Chandler Publishing.

BRADLEY, R. (1993). Children's home environments, health, behavior, and intervention efforts: A review using the HOME inventory as a marker measure. Genetic, Social and General Psychology Monographs, 119, 439-490.

BRADLEY, R., CALDWELL, B., \& ELARDO, R. (1977). Home environment, social status, and mental test performance. Journal of Educational Psychology, 69, 697-701.

BRADLEY, R., CALDWELL, B., ROCK, S., BARNARD, K., GRAY, C., HAMMOND, M., MITCHELL, S., SIEGEL, L., RAMEY, C., GOTTFRIED, A., \& JOHNSON, D. (1989). Home environment and cognitive development in the first 3 years of life: A collaborative study involving six sites and three ethnic groups in north America. Developmental Psychology, 25, 217-235.

BRADLEY, R., WHITESIDE, L., CALDWELL, B., CASEY, P., KELLEHER, K., POPE, S., SWANSON, M., BARRETT, K. \& CROSS, D. (1993). Maternal IQ, the home environment, and child IQ in low birthweight, premature infants. International Journal of Behavioral Development, 16, 61-74.

BRONFENBRENNER, U. (1986). Ecology of the family as a context for human development: Research perspectives. Developmental Psychology, 22, 723-742.

BRYK, A., \& RAUDENBUSH, S. (1987). Application of hierarchical linear models to assessing change. Psychological Bulletin, 101, 147-158.

BURCHINAL, M., \& APPELBAUM, M. (1991). Estimating individual developmental functions: Methods and their assumptions. Child Development, 62, 23-43.

CALDWELL, B., \& BRADLEY, R. (1978). Manual for the Home Observation for Measurement of the Environment. Little Rock: University of Arkansas.

ELDER, G. (1998). The life course as developmental theory. Child Development, $69,1-15$. 
FLYNN, J. (1987). Massive IQ gains in 14 nations: What IQ tests really measure. Psychological Bulletin, 95, 29-51.

FRANCIS, D., COPELAND, D., \& MOORE, B. (1994). Neuropsychological changes in children with cancer: The treatment of missing data in longitudinal studies. Neuropsychology Review, 4, 199-222.

FRANCIS, D., FLETCHER, J., STEUBING, K., DAVIDSON, K, \& THOMPSON, N. (1991). Analysis of change: Modeling individual growth. Journal of Consulting and Clinical Psychology, 59, 27-37.

GARDNER, H. (1999). Intelligence reframed: Multiple intelligences for the $21^{\text {st }}$ century. New York: Basic Books.

GOTTESMAN, I. I. (1974). Developmental genetics and ontogenetic psychology: Overdue detente and propositions from a matchmaker. In A. Pick (Ed.), Minnesota symposium on child psychology. Minneapolis: University of Minnesota Press.

GOTTFRIED, A. (1984). Home environment and early cognitive development: Integration, meta-analysis, and conclusions. In A. Gottfried (Ed.), Home environment and early cognitive development. Orlando, FL: Academic Press.

GOTTFRIED, A., \& GOTTFRIED, A. (1984). Home environment and cognitive development in young children of middle-socioeconomic-status families. In A. Gottfried (Ed.), Home environment and early cognitive development. Orlando, FL: Academic Press.

HORN, J. (1989). Models of intelligence. In R. Linn et al. (Eds.), Intelligence: Measurement, theory, and public policy. Champaign: University of Illinois Press.

HUNTER, J. E., \& SCHMIDT, F. L. (1990). Methods of meta-analysis: Correcting error and bias in research findings. Newbury Park, CA: Sage.

KREFT, I., DE LEEUW, J., \& AIKEN, L. (1995). The effect of different forms of centering on hierarchical linear models. Multivariate Behavioral Research, 30, $1-21$.

MATHENY, A. (1989). Assessment of infant mental development: Toward a broader perspective. Clinics in Perinatology, 16, 565-576.

MCCALL, R. B., APPELBAUM, M. I., \& HOGARTY, P. S. (1973). Developmental changes in mental performance. Monographs of the Society for Research in Child Development, 150, 38.

MOLFESE, V., DILALLA, L., \& BUNCE, D. (1997). Prediction of the intelligence scores of 3- to 8-year-old children by home environment, socioeconomic status, and biomedical risks. Merrill-Palmer Quarterly, 43, 219-234.

MOLFESE, V., DILALLA, L., \& LOVELACE, L. (1995). Perinatal, home environment, and infant measures as successful predictors of preschool cognitive and verbal abilities. International Journal of Behavioral Development, 18, $1-19$. 
MOLFESE, V., HOLCOMB, L., \& HELWIG, S. (1994). Biomedical and socialenvironmental influences on cognitive and verbal abilities in children 1 to 3 years of age. International Journal of Behavioral Development, 17, 271-287.

PLOMIN, R., DEFRIES, J. C., \& LOEHLIN, J. C. (1977). Genotype-environment interaction and correlation in the analysis of human behavior. Psychological Bulletin, 84, 309-322.

ROWE, D. C., JACOBSON, K. C., \& VAN DEN OORD, E. J. C. G. (1999). Genetic and environmental influences on vocabulary IQ: Parental education level as a moderator. Child Development, 70, 1151-1162.

SCARR, S. (1992). Developmental theories for the 1990s: Development and individual differences. Child Development, 63, 1-19.

SCARR, S. (1985). Constructing psychology: Making facts and fables for our times. American Psychologist, 40, 499-512.

SCARR, S., \& MCCARTNEY, K. (1983). How people make their own environments: A theory of genotype-> environment effects. Child Development, 54, 424-435.

SCHIAMBERG, L., \& LEE, C. (1991, April). Predictors of verbal intelligence and behavioral problems among 4-year-old children. Paper presented at the biennial meeting of the Society for Research in Child Development, April, Seattle.

SNIJDERS, T., \& BOSKER, R. (1994). Modeled variance in two-level models. Sociological Methods and Research, 22, 342-363.

STERNBERG, R. (1997). Thinking styles. New York: Cambridge University Press.

STERNBERG, R., \& KAUFMAN, J. (1998). Human abilities. Annual Review of Psychology. Palo Alto, Ca: Annual Review

THORNDIKE, R., HAGEN, E., \& SATTLER, J. (1986). Guide for administering and scoring the fourth edition Stanford-Binet Intelligence Scale. Chicago: Riverside.

TURKHEIMER, E., GOLDSMITH, H. H., \& GOTTESMAN, I. I. (1995). Commentary-Some conceptual deficiencies in "developmental" behavior genetics. Human Development, 38, 142-153.

WECHSLER, D. (1991). Wechsler Intelligence Scale for Children-III. San Antonio: Psychological Corporation.

WILLETT, J. (1988). Questions and answers in the measurement of change. Review of Research in Education, 15, 345-422. 